\title{
Biochar Aerogel Decorated with Thiophene S Manipulated 5-membered Rings Boosts Nitrogen Fixation
}

\section{Xiaokang Chen}

Qingdao University

\section{Lijie Zhang}

Qingdao University

\section{Wenjia Xu}

Qingdao University

\section{Xin Ding}

Qingdao University

\section{Shuai Chen}

Institute of Coal Chemistry

\section{Xilin She}

Qingdao University

Xiangxin Guo

Qingdao University

Chung-Li Dong

Tamkang University https://orcid.org/0000-0002-4289-4677

\section{Yucheng Huang}

Tamkang University

\section{Lixue Zhang}

Qingdao University

\section{Shaohua Shen}

Xi'an Jiaotong University https://orcid.org/0000-0001-8536-7386

Dongjiang Yang ( $\nabla$ d.yang@qdu.edu.cn )

Qingdao University

\section{Article}

Keywords: algae, marine biogenic sulfur (S), dimethylsulfide (DMS)

Posted Date: June 9th, 2021

DOl: https://doi.org/10.21203/rs.3.rs-590418/v1 
License: (c) (i) This work is licensed under a Creative Commons Attribution 4.0 International License. Read Full License

Version of Record: A version of this preprint was published at Applied Catalysis B: Environmental on April 1st, 2022. See the published version at https://doi.org/10.1016/j.apcatb.2022.121425. 


\section{Abstract}

Algae, which contains most of the marine biogenic sulfur (S), is the main producer of dimethylsulfide (DMS). The oxidation products of DMS (methanesulfonic acid (MSA) and non-sea salt sulfates (nssSO42-)) are important contributors to acid rain acidity ( 40\%) and have great influence on global climate change and acid rain formation. The biogenic $S$ of red algae mainly exists in carrageenan molecules, the polysaccharide extract of red algae. In this work, the carrageenan biogenic $S$ was fixed into biochar aerogel (SCA) synchronically by pyrolysis with the assistance of the unique hydrogel property of carrageenan. During this process, $89 \%$ of $C$ and $96 \%$ of marine biogenic $S$ are preserved in SCA, efficiently preventing the loss of $\mathrm{C}$ and $\mathrm{S}$ element. More importantly, the thiophene S structure in SCA framework derived from the marine biogenic $S$ could endow the carbon aerogel superior electrocatalysis activity by regulating the charge density of adjacent $\mathrm{C}$ atoms. For instance, thiophene $\mathrm{S}$ structure can promote the cleavage and protonation of $\mathrm{N} 2$ molecules and efficiently lower the energy barrier of the promote the protonation of N2, thus greatly enhance the activity of electrocatalytic NRR. This study provided a promising avenue for the synchronization fixation of marine biogenic $S$ and $C$ to reduce the the formation of acid rain and carbon dioxide emissions. It also developed a green and sustainable way to synthesize high-performance biochar materials for advanced energy conversion.

\section{Main Text}

Sulfur (S) cycle is a process of transformation and reciprocation of the S elements in the ecosystem and environment (Supplementary Figure 1), wherein the acid rain is a big problem due to its great harm to ecological environment, agriculture and even human beings. ${ }^{1,2}$ Algae, which contains most of the marine biogenic $S$, is the main producer of dimethylsulfonio-propionate (DMSP) and contributes $~ 40 \%$ of the acidity of acid rain. ${ }^{3,4}$ Besides, the decay of algae will cause large amount of $S$ and $C$ elements to be lost in the atmosphere to form toxic substances or greenhouse gases. ${ }^{5,6}$ Therefore, it is urgent and meaningful to explore effective strategies to prevent the loss of $S$ and $C$ elements from the perspective of sustainable and environmental protection. In red algae, most of the biogenic $S$ is found in polymers called carrageenan. Carrageenan contains a large number of sulfonic groups and can be easily treated to obtain porous biochar aerogel structure. ${ }^{7}$ Surprisingly, carrageenan has the properties of temperaturesensitive gel, and its molecular chain will show "spiral" transformation during the cooling process. The carrageenan with "spiral" molecular chains has potential to generate three-dimensional (3D) hierarchical porous biochar aerogels. ${ }^{8}$ Recently, biochar materials and their applications in emerging energy storage and conversion have become an attractive topic in the field of sustainable development. ${ }^{9,10}$ The utilization of biochar materials could play the role of carbon sequestration and carbon reduction, and greatly reduce the emission of $\mathrm{CO}_{2}$, which is an effective way to mitigate global warming. ${ }^{11}$ In addition, the introduction of $S$ into biochar can endow the carbon aerogel superior electrocatalysis activity by regulating the charge density of adjacent $\mathrm{C}$ atoms, ${ }^{12,13}$ and thus improve the added value of biochar materials. Therefore, large-scale utilization of carrageenan to synthesize biochar can not only play an 
important role in fixing S and C, but also provide an excellent electrocatalyst for advanced energy conversion.

Ammonia $\left(\mathrm{NH}_{3}\right)$ is one of the most important fundamental chemicals for humans. Since Davy et al. discovered the electrochemical $\mathrm{N}_{2}$ reduction reaction (NRR), it has become a promising alternative to traditional industrial ammonia synthesis (Haber-Bosch) approach for the synthesis of $\mathrm{NH}_{3}{ }^{14,15,16}$ Compared to traditional Haber-Bosch process, the electrocatalytic process using the sustainable protons in water to replace the hydrogen gas used in industry, and convert $\mathrm{N}_{2}$ into $\mathrm{NH}_{3}$ by controlling the potential, which greatly reduces energy consumption and carbon dioxide emissions, and promote the sustainable development of human society. ${ }^{17,18}$ However, the chemical superstability of $\mathrm{N}_{2}$ molecules make the realization of electrocatalytic NRR difficult, which requires the search of catalysts with special active sites to accelerate ammonia synthesis. ${ }^{19}$ The designed NRR electrocatalysts should exhibit excellent apparent activity to efficiently promote the diffusion of solvated gas $\left(\mathrm{N}_{2}\right)$ and electrolytes, and exhibit outstanding intrinsic activity to improve the catalytic ability of active sites, thus accelerating the cleavage and protonation of $\mathrm{N}_{2}$ to enhance the activity of NRR. ${ }^{19}$

Herein, we fabricated biochar aerogel electrocatalysts decorated with thiophene S (SCA) for electrochemical NRR by directly pyrolyzing carrageenan. During this process, $89 \%$ carbon was retained and converted to biochar structure. Meanwhile, $96 \%$ marine biogenic $S$ was cured to thiophene $S$ and oxidized S species into the biochar, efficiently prevents the loss of S element. More importantly, the thiophene $S$ structure in the SCA achieves excellent electrochemical $\mathrm{N}_{2}$ reduction reaction (NRR) performance with a highest $\mathrm{NH}_{3}$ yield rate of $36.69 \mathrm{\mu g} \mathrm{h}^{-1} \mathrm{mg}^{-1}$ cat and Faradaic efficiency (FE) of $8.72 \%$ in acid solution under ambient conditions. Density functional theory (DFT) calculation results further confirm that thiophene $\mathrm{S}$ structure can effectively regulate the charge density of adjacent $\mathrm{C}$ atoms to facilitate the activation of $\mathrm{N}_{2}$ molecules. The preferable reaction pathway for $\mathrm{NRR}$ is ${ }^{*} \mathrm{~N}_{2} \rightarrow * \mathrm{NNH} \rightarrow$ $\star \mathrm{NHNH} \rightarrow{ }^{*} \mathrm{NHNH}_{2} \rightarrow * \mathrm{NH}_{2} \mathrm{NH}_{2} \rightarrow{ }^{*} \mathrm{NH}_{2} \rightarrow{ }^{*} \mathrm{NH}_{3}$.

As illustrated in Figure $1 \mathrm{a}$, the $\mathrm{S}$ element in $\nabla$-carrageenan was fixed in the SCA framework and converted to thiophene $S$ and oxidized $S$ species by using a simple freeze-drying and pyrolysis process. Specifically, the hot aqueous carrageenan solution converted to transparent hydrogel after cooling down at a temperature lower than $80^{\circ} \mathrm{C}$, since the random coiled carrageenan macromolecules were cross-linked to form "double-helix" structure. ${ }^{20}$ After subsequent freeze-drying, the carrageenan hydrogel converted to highly porous aerogel. Finally, the carrageenan aerogel was pyrolyzed at $\mathrm{T}^{\circ} \mathrm{C}(600$, 700, and 800) under Ar atmosphere to obtain ultralight S-doped carbon aerogels (SCA-T). Besides, the inductively coupled plasma atomic emission spectroscopy (ICP-AES) also was performed to prove that no common metals existed in SCA electrocatalyst (Supplementary Table 1). The as-synthesized samples were characterized by using scanning electron microscopy (SEM) and transmission electron microscopy (TEM). Obviously, as displayed in the SEM (Figure 1b-c) and TEM image (Figure 1d), the SCA is a 3D self-supporting porous network structure. A large amount of macropores, mesopores (25-50 nm) and 
micropores can be observed on the surface of SCA. The mesopores and micropores can provide large electrode/electrolyte interface to accelerate electron transfer. ${ }^{21,22}$ EDS mapping spectrum indicates that $\mathrm{C}, \mathrm{S}$ and $\mathrm{O}$ elements are uniformly dispersed in the whole SCA (Figure 1e).

Figure 2a displays the X-ray diffraction (XRD) patterns of SCA-T. The two diffraction peaks (23.0 and $43.5^{\circ}$ ) are assigned to the (002) and (101) diffraction plane of graphitic structure in SCA matrix. The $\mathrm{N}_{2}$ adsorption-desorption isotherms and pore size distribution of SCA-T are shown in Figure 2b. The adsorption occurred at the relative pressure $\left(P / P_{0}<0.02\right)$ indicates the existence of micropores in the samples, which is consistent with the results show in the TEM above. The H4-type hysteresis loop originates from the presence of mesopores. ${ }^{23}$ The SCA-700 owns the highest Brunauer-Emmett-Teller (BET) surface area $\left(1668.9 \mathrm{~m}^{2} \mathrm{~g}^{-1}\right)$. From the pore size distribution, the pore diameters are located at $1.0 \mathrm{~nm}$ (micropores) and $\sim 2.3 \mathrm{~nm}$ (small mesopores) by the desorption branch of isotherm calculation. The appearance of micropores and mesopores in SCA-T is due to the decomposition of sulfur and oxygen groups $\left(-\mathrm{SO}_{4} \mathrm{H},-\mathrm{COOH}\right.$, and $\left.-\mathrm{OH}\right)$ in carrageenan macromolecules. The high BET surface area combined with hierarchical porous structure could efficiently promote the diffusion of solvated gas $\left(\mathrm{N}_{2}\right)$ and electrolytes, thus accelerating the protonation of $\mathrm{N}_{2}$ to enhance the activity of NRR. ${ }^{18}$ The thermogravimetric analysis (TG/DTG) and the corresponding mass spectra (TG-MS) were been carried out to reveal the pyrolysis process of carrageenan aerogel (Figure 2d). The DTG curve shows three more distinct stages of heat gains at $207^{\circ} \mathrm{C}, 310^{\circ} \mathrm{C}$ and $726^{\circ} \mathrm{C}$ during the whole pyrolysis process. Meanwhile, the first, second and third major weight loss steps could be found in the TG curve, that occur in the temperature range of $190-221^{\circ} \mathrm{C}, 227-380^{\circ} \mathrm{C}$ and $672-741^{\circ} \mathrm{C}$, respectively (Figure $2 \mathrm{C}$ ). As shown in the Figure $2 d$, the corresponding TG-MS curves display the volatiles from aerogel pyrolysis are $\mathrm{CO}_{2}(\mathrm{~m} / \mathrm{z}$ : 44$)$, $\mathrm{H}_{2} \mathrm{O}(\mathrm{m} / \mathrm{z}: 18), \mathrm{SO}_{2}(\mathrm{~m} / \mathrm{z}: 64)$ and $\mathrm{CO}(\mathrm{m} / \mathrm{z}: 28)$. The sharp peaks could be found at the temperature of $194{ }^{\circ} \mathrm{C}$ from the Pink and purple curves $\left(\mathrm{H}_{2} \mathrm{O}\right.$ and $\left.\mathrm{CO}_{2}\right)$, respectively, which corresponds to the first rapid weight loss step $\left(190-221^{\circ} \mathrm{C}\right)$ of the TG curve. Besides, the peaks at $296^{\circ} \mathrm{C}$ in pink and orange curves $\left(\mathrm{CO}_{2}\right.$ and $\left.\mathrm{SO}_{2}\right)$, and the peaks at $700{ }^{\circ} \mathrm{C}$ in pink and olive curves $\left(\mathrm{CO}_{2}\right.$ and $\left.\mathrm{CO}\right)$ could be ascribed to the second $\left(227-380^{\circ} \mathrm{C}\right)$ and third $\left(672-741^{\circ} \mathrm{C}\right)$ major decomposition steps, respectively, corresponding to the TG. Thus, during the pyrolysis process, the oxygen-containing groups $\left(-\mathrm{SO}_{4} \mathrm{H}, \mathrm{C}-\mathrm{O}-\mathrm{C}\right.$ and $-\mathrm{OH}$ et al.) in carrageenan molecular are converted to $\mathrm{H}_{2} \mathrm{O}, \mathrm{CO}_{2}, \mathrm{SO}_{2}$ and $\mathrm{CO}$ by the $\mathrm{TG}$ and TG-MS analysis. TG-Fourier transform infrared spectriscopy spectra (TG-FTIR) was carried out to further confirm the volatiles components in the thermal decomposition of carrageenan aerogel.

As shown in the 3D TG-FTIR spectrum, the peaks at wavenumbers $3851-3253 \mathrm{~cm}^{-1}$ indicated the existence of $\mathrm{H}_{2} \mathrm{O}$ by the stretching vibration of $\mathrm{O}-\mathrm{H}$ bonds. ${ }^{24}$ The adsorption bands at $2400-2240 \mathrm{~cm}^{-1}$ were assigned to $\mathrm{CO}_{2}$ and $\mathrm{CO}$. The peaks at wavenumber $1700-1600 \mathrm{~cm}^{-1}$ and $1600-1520 \mathrm{~cm}^{-1}$ were the stretching vibration of $\mathrm{C}=0$ bonds and $\mathrm{C}=\mathrm{C}$ bonds, respectively, which confirms the existence of some carbonyl compounds (such as ketones, alkane, and acids). ${ }^{25}$ The peaks at wavenumbers $900-1131 \mathrm{~cm}^{-1}$ representing the $\mathrm{S}=0$ bonds stretching vibration, which indicated the co-existence of oxidized $\mathrm{S}$ and sulfonate groups. In addition, at the wave number of $1200-1354 \mathrm{~cm}^{-1}$, no peak was found in the original 
carrageenan, but with the increase of pyrolysis temperature, the C-S-C vibration peaks representing the thiophene-S structure began to appear. ${ }^{26}$ The X-ray photoelectron spectroscopy (XPS) measurement of SCA-700 was carried out to probe the chemical environments of C, S and 0 elements (Figure 2f, Supplementary Figure 2). As shown in high-resolution S 2p spectra, the thiophene $S\left(S 2 p_{1 / 2} 163.7\right.$ and $S$ $2 p_{1 / 3} 165.1 \mathrm{eV}$ ) was determined to be the dominant $\mathrm{S}$ species. ${ }^{27}$ The residual $\mathrm{S}$ located at 168.4 and $169.2 \mathrm{eV}$ are attributed to the $-\mathrm{C}-\mathrm{SO}_{\mathrm{X}}$ species. ${ }^{28,29}$ Furthermore, the $\mathrm{S}$ K-edge X-ray absorption structure (XAS) spectra further confimed the existence of thiophene $S$ structure. As shown in the Figure $2 \mathrm{~g}$, the two major absorption bands were observed in the XAS of SCA-700 spectra, representing thiophene S (2471.1 $\mathrm{eV}$ ) and oxidized-S (2481.1 eV), respectively. ${ }^{30}$ However, in the carrageenan XAS spectra, only sulfonate $(2479.8 \mathrm{eV})$ and oxidized-S (2481.1 eV) are visible, which indicates that the sulfonate and oxidized-S in carrageenan were transformed or removed into thiophene $S$ and oxidized-S after the fixation process. ${ }^{31}$ The XPS and XAS results demonstrated that the contained $\mathrm{S}$ in carrageenan was successfully fixed in a carbon framework and converted to thiophene $S$ and oxidized $S$ (Figure $2 \mathrm{~h}$ ).

For NRR tests, we used the carbon paper coated with SCA-T as working electrode. $\mathrm{The}^{\mathrm{NH}} \mathrm{H}_{3}$ yield rates and FEs were obtained by spectrophotometry with indophenol blue method (Supplementary Figure 3, Supplementary Figure 4). ${ }^{32}$ Figure 3 a shows the NRR performance of SCA-T in $0.1 \mathrm{M} \mathrm{HCl}$ electrolyte. Apparently, the sample of SCA-700 exhibits much higher $\mathrm{NH}_{3}$ yield rates than SCA-600 and SCA-800, attributing to its higher specific surface area. Then, we measured the linear sweep voltammograms (LSVs) in Ar and $\mathrm{N}_{2}$-saturated $0.1 \mathrm{M} \mathrm{HCl}$ electrolyte to further appraise the NRR electrocatalytic activity of most active SCA-700 (Figure 3b). Apparently, the current density under $\mathrm{N}_{2}$ is higher than that under $\mathrm{Ar}$, indicating the occurrence of eletrocatalytic $\mathrm{N}_{2}$ reduction. ${ }^{33}$ The chronoamperometry curves at different working potentials implying that as-prepared SCA-700 can ensure the stability for reaction process (Figure 3c).${ }^{34}$ By calculation, Figure $3 \mathrm{~d}$ displayed the corresponding $\mathrm{NH}_{3}$ yield rates and FEs of SCA-700 under different potentials. The $\mathrm{N}_{2}$ can be reduced to $\mathrm{NH}_{3}$ at the potential of $-0.1 \mathrm{~V}$ to $-0.5 \mathrm{~V}$ (vs. RHE). Besides, both $\mathrm{NH}_{3}$ yield rate and $\mathrm{FE}$ improve as the potential is negatively shifted, and achieve the highest value at the potential of $-0.3 \mathrm{~V}$. The highest $\mathrm{NH}_{3}$ yield rate and $\mathrm{FE}$ are $36.69 \mu \mathrm{g} \mathrm{h}^{-1} \mathrm{mg}^{-1}$ cat and $8.72 \%$, respectively. Obviously, the $\mathrm{NH}_{3}$ yield rate of SCA-700 is higher than the most of the previously reported metal-free electrocatalysts (Figure $3 e$ and Supplementary Table 2). In addition, to further confirm that the detected $\mathrm{NH}_{3}$ was generated via the $\mathrm{N}_{2}$ fixation process over SCA-700, we also performed electrolysis in Ar-saturated solution and pure carbon paper in $\mathrm{N}_{2}$-saturated solution at $-0.3 \mathrm{~V}$ for $2 \mathrm{~h}$. The corresponding UV-Vis absorption spectra show no detectable $\mathrm{NH}_{3}$ generated in either condition (Supplementary Figure 5). Furthermore, we tested the ${ }^{1} \mathrm{H}$ NMR analysis of the electrolyte fed by ${ }^{15} \mathrm{~N}_{2}$ and ${ }^{14} \mathrm{~N}_{2}$ after electrolytic reaction at $-0.3 \mathrm{~V}$ to further determine the $\mathrm{N}$ source of produced $\mathrm{NH}_{3}$. As shown in Figure $3 \mathrm{f}$, only the two peaks of ${ }^{15} \mathrm{NH}_{4}{ }^{+}$were found in the ${ }^{15} \mathrm{~N}$ saturated electrolyte, indicating that $\mathrm{N}_{2}$ is the only source of produced $\mathrm{NH}_{3}$ by SCA-700. Notably, the $\mathrm{N}_{2} \mathrm{H}_{4}$ (by-product) could be detected by spectrophotometry with the method of Watt and Chrisp. ${ }^{35}$ The detecting calibration curve of $\mathrm{N}_{2} \mathrm{H}_{4}$ is 
shown in Supplementary Figure 6. We failed to detect the production of $\mathrm{N}_{2} \mathrm{H}_{4}$ in $\mathrm{N}_{2}$-saturated electrolyte (after charging at $-0.3 \mathrm{~V}$ for $2 \mathrm{~h}$ ), indicating that SCA-700 is an electrocatalyst with excellent selectivity for NRR (Supplementary Figure 7). Then, we performed cycling and chronoamperometric tests of SCA-700 in $0.1 \mathrm{M} \mathrm{HCl}$ media to study the stability of catalyst for practical. As shown in the Figure $3 \mathrm{~g}$, no obvious decline in $\mathrm{NH}_{3}$ yield rate and FE of SCA-700 after 5 times cycling tests. And after the NRR test lasted for $10 \mathrm{~h}$, the SCA-700 shows a relatively stable current density at $-0.3 \mathrm{~V}$ (Supplementary Figure 8).

In order to further emphasize the significance of the fixed $\mathrm{S}$ unit in $\mathrm{N}_{2}$ fixation, we annealed the SCA-700 at $1100{ }^{\circ} \mathrm{C}$ to remove $S$ atoms in SCA, fabricating SCA-700-1100. The XPS of SCA-700-1100 was displayed in Supplementary Figure 9. Apparently, only very weak peaks are observed in $S 2 p$ spectra of SCA-700-1100, indicating that most of $S$ atoms are removed after the pyrolysis at $1100{ }^{\circ} \mathrm{C}$. The atomic percentage of S content is largely reduced from $4.64 \%$ for SCA -700 to $0.15 \%$ for SCA-700 -1100 (Supplementary Table 3). As shown in Figure 3h, the SCA-700-1100 only delivers a yield rate of $8.2 \mu \mathrm{g}$ $\mathrm{h}^{-1} \mathrm{mg}^{-1}$ cat, much lower than the yield rate of SCA-700. The result indicates that fixed $\mathrm{S}$ unit is most likely the origin of the boosted NRR performance in SCA-700. In addition, as shown in electrochemical impedance spectroscopy (EIS) (Supplementary Figure 10), the charge transfer resistance $\left(R_{c t}\right)$ value of SCA-700 is lower than SCA-700-1100, indicating that the fixed S can improve the conductivity and fast the charge transport ability. ${ }^{18}$ Given that HER is the primary competitive reaction of NRR, we tested the HER performances of SCA-700 and SCA-700-1100 in acid solution as well. Obviously, as shown in Figure $3 i$, the SCA-700 shows lower HER catalytic activity than SCA-700-1100, which indicated that the fixed $S$ unit is the key to inhibit HER activity and promote NRR activity. ${ }^{36,37}$ However, the prepared SCA700 contains two types of $S$ units, thiophene $S$ and $S$ oxides, which is difficult to verify experimentally which of the two $S$ units is the main active species for catalytic $\mathrm{N}_{2}$ reduction. Therefore, we compared the Gibbs free energy of $N_{2}$ protonation $\left(\Delta G_{*_{N} 2 H}\right)$ at different sites of the two $S$ units to determine the best active unit for NRR by DFT calculations. Apparently, compared with thiophene $S$, the oxidized $S$ unit exhibits very high $\Delta \mathrm{G}_{{ }_{\mathrm{N}} 2 \mathrm{H}}$ in the $\mathrm{N}_{2}$ protonation process, and is ineffective on electrocatalytic $\mathrm{N}_{2}$ fixation (Supplementary Figure 11 and Supplementary Table 4). Based on the above results, the thiophene $S$ unit is the main active site for $\mathrm{N}_{2}$ fixation in SCA-700 electrocatalysts.

To reveal the role of thiophene S structure of SCA on NRR, we studied the electronic structure of SCA and the Gibbs free energy diagram of NRR on SCA by the DFT calculations. As shown in Figure 4a, we constructed computational calculations on two types of models (pure carbon substrate $(G)$ and thiophene S 5-membered ring on carbon substrate (S-G-n, $n$ represents the position of active sites in Figure 4a). Firstly, the charge density difference is calculated to study the electron transfer behavior between $\mathrm{N}_{2}$ and $\mathrm{S}-\mathrm{G}$ or $\mathrm{G}$. As shown in Figure $4 \mathrm{~b}$, more electron transfer between $\mathrm{S}-\mathrm{G}$ and $\mathrm{N}_{2}$ is observed than that between $G$ and $N_{2}$. Figure $4 c$ compares the density of states (DOS) for $G$ and $S-G$. The DOS of $S-G$ in Fermi level is stronger than that of $G$, which indicates that the $S-G$ has better conductivity than G. ${ }^{38}$ Gibbs free energy of $N_{2}$ protonation $\left(\Delta G_{* N}{ }_{*}\right)$ was calculated to highlight the effect of thiophene $S$ for $\mathrm{N}_{2}$ fixation (Figure 4d). Apparently, the S-G-2 exhibits much lower $\Delta \mathrm{G}_{{ }_{\mathrm{N}} 2 \mathrm{H}}(1.12 \mathrm{eV}$ ) than that of $\mathrm{G}$ 
$(2.59 \mathrm{eV})$, indicating that thiophene $\mathrm{S}$ can reduce the energy barrier of $\mathrm{N}_{2}$ protonation and enhance the NRR activity by regulating the charge density of adjacent $C$ atoms (Supplementary Table 4). It is known that the $\mathrm{N}_{2}$ molecules can be absorbed in a vertical or horizontal way, and the adding $\mathrm{H}$ atoms can perform hydrogenation to the catalyst via a distal or alternating mechanism for $\mathrm{NH}_{3}$ synthesis. As shown in Figure 4e and Supplementary Figure 12, we performed three possible reaction pathways for $\mathrm{NH}_{3}$ synthesis on S-G. By contrast, the preferable pathway for NRR on S-G is ${ }^{*} \mathrm{~N}_{2} \rightarrow{ }^{*} \mathrm{NNH} \rightarrow{ }^{*} \mathrm{NHNH} \rightarrow$ ${ }^{*} \mathrm{NHNH}_{2} \rightarrow{ }^{*} \mathrm{NH}_{2} \mathrm{NH}_{2} \rightarrow{ }^{*} \mathrm{NH}_{2} \rightarrow{ }^{*} \mathrm{NH}_{3}$ (vertical alternating pathway). The rate-determining step (RDS) of vertical alternating pathway is the protonation of pre-absorbed $\mathrm{N}_{2}\left({ }^{*} \mathrm{~N}_{2} \rightarrow * \mathrm{NNH}\right)$. The energy barrier (1.12 $\mathrm{eV})$ of RDS in vertical alternating pathway is much lower than that in vertical distal pathway $(1.68 \mathrm{eV})$ and horizon alternating pathway $(2.62 \mathrm{eV})$. The thiophene $\mathrm{S}$ unit is critical factor to accelerate $\mathrm{N}_{2}$ dissociation and protonation on carbon substrate. Therefore, the lowest energy barrier on S-G predicts that the SCA is an ideal electrocatalyst for catalyzing NRR.

In summary, large-scale exploitation and utilization of algae could effectively fix $\mathrm{S}$ and $\mathrm{C}$, thus preventing the emission of sulfur dioxide and carbon dioxide. In this work, we synchronously fix the carrageenan biogenic $S$ into the SCA by using pyrolysis with the assistance of the unique hydrogel property of carrageenan. It not only perfectly completes the role of $\mathrm{C}$ and $\mathrm{S}$ fixation, but also the generated SCA exhibits excellent NRR activity and selectivity. Under ambient conditions, the yield rate of $\mathrm{NH}_{3}$ and FE can reach $36.69 \mathrm{\mu} \mathrm{h}^{-1} \mathrm{mg}^{-1}$ cat and $8.72 \%$, respectively, which exceeds mostly reported metal-free catalysis. DFT calculation results suggested that the thiophene $S$ structure could reduce the energy barrier of $\mathrm{N}_{2}$ protonation by regulating the electronic structure of adjacent $\mathrm{C}$ atoms. The preferable reaction pathway for $\mathrm{NRR}$ was ${ }^{*} \mathrm{~N}_{2} \rightarrow{ }^{*} \mathrm{NNH} \rightarrow{ }^{*} \mathrm{NHNH} \rightarrow{ }^{*} \mathrm{NHNH}_{2} \rightarrow{ }^{*} \mathrm{NH}_{2} \mathrm{NH}_{2} \rightarrow{ }^{*} \mathrm{NH}_{2} \rightarrow{ }^{*} \mathrm{NH}_{3}$. This study opens up a new avenue for the synchronization fixation of marine biogenic $\mathrm{S}$ and $\mathrm{C}$, and explores a sustainable strategy to synthesize high-performance biochar materials for electrochemical.

\section{Declarations}

Supplementary Information is available in the online version of the paper.

Acknowledgements This work is financially supported by the National Nature Science Foundation of China (Nos. 51473081, 51672143 and 81502246), Taishan Scholars Program, Outstanding Youth of Natural Science in Shandong Province (JQ201713), ARC Discovery Project (No. 170103317), and the Key Research and Development Program of Shandong Province (Project No. 2017GSF18128).

Author Contributions X.K.C. and L.J.Z. contributed equally to this work. D.J.Y. designed the experiments. W.J.X. performed the theoretical calculations. X.K.C. performed electrochemical experiments. S.C and Y.W.C conducted aberration-corrected high-resolution transition electronic microscope measurement. X.L.S performed X-ray absorption structure measurement. X.K.C., L.J.Z., and D.J.Y. wrote the manuscript with input from all authors. All authors discussed the obtained results. 
Author Information Reprints and permissions information is available at www.nature.com/reprints. The authors declare no competing financial interests. Readers are welcome to comment on the online version of the paper. Publisher's note: Springer Nature remains neutral with regard to jurisdictional claims in published maps and institutional affiliations. Correspondence and requests for materials should be addressed to D.J.Y. (d.yang@qdu.qdu.cn).

\section{References}

1 Dong, D. et al. Non-linear direct effects of acid rain on leaf photosynthetic rate of terrest plants. Environ. Pollut. 231, 1442-1445 (2017).

2 Menz, F.C. et al. Acid rain in Europe and the United States: an update. Energy. Sci. Policy 7, 253-265 (2004).

3 Curson, A.R.J. et al. DSYB catalyses the key step of dimethylsulfoniopropionate biosynthesis in many phytoplankton. Nat Microbiol. 3, 430-439 (2018).

4 Greene, R.C. et al. Biosynthesis of d imethyl-3-propiothetin. J. Bio Chem. 237, 2251-2254 (1962).

5 Archer, S. et al. Phytoplankton taxa, irradiance and nutrient availability determine the seasonal cycle of DMSP in temperate shelf seas. Mar Ecol Prog Ser. 394, 111-124 (2009).

$6 \quad$ Bates, T. S. et al. Dimethylsulfide (DMS) in theequatorial Pacific Ocean (1982 to 1996): Evidence of a climate feedback? Geophys Res Lett. 24, 861-864 (1997).

7 Ficko-Blean, E. et al. Carrageenan catabolism is encoded by a complex regulon in marine heterotrophic bacteria. Nat. Commun. 8, 1685 (2017).

$8 \mathrm{Li}, \mathrm{D}$. et al. Double-helix structure in carrageenan-metal hydrogels: A general approach to porous metal sulfides/carbon aerogels with excellent sodium-ion storage. Angew. Chem. Int. Ed. 55, 15925-15928 (2016).

$9 \mathrm{Li}, \mathrm{J}$. et al. Interfacial solar steam generation enables fast-responsive, energy-efficient, and lowcost off-grid sterilization. Adv. Mater. 1, 1805159 (2018).

10 Liu, W. J. et al. Emerging applications of biochar-based materials for energy storage and conversion. Energy. Environ. Sci. 12, 1751-1779 (2019).

11 Zhang, T. et al. Ti-Sn-Ce/bamboo biochar particle electrodes for enhanced electrocatalytic treatment of coking wastewater in a threedimensional electrochemical reaction system. J. Clean. Prod. 258, 120273 (2020).

$12 \mathrm{Li}$, D. et al. Metal-Free Thiophene-Sulfur Covalent Organic Frameworks: Precise and Controllable Synthesis of Catalytic Active Sites for Oxygen Reduction. J. Am. Chem. Soc.. 18, 8104-8108 (2020). 
$13 \mathrm{Li}, \mathrm{D}$. et al. A defect-driven metal-free electrocatalyst for oxygen reduction in acidic electrolyte. Chem. 4, 2345-2356 (2018).

14 Gong, Y. T. et al. Ternary intermetallic LaCoSi as a catalyst for $\mathrm{N}_{2}$ activation. Nat. Catal. 1, 178-185 (2018).

15 Kitano, M. et al. Ammonia synthesis using a stable electride as an electron donor and reversible hydrogen store. Nat. Chem. 4, 934-940 (2012).

16 Rosca, V., Duca, M., DeGroot, M. T. \& Koper, M. T. M. Nitrogen cycle electrocatalysis. Chem. Rev. 109, 2209-2244 (2009).

17 Ma, J. L. et al. Reversible Nitrogen Fixation Based on a Rechargeable Lithium-Nitrogen Battery for Energy Storage. Chem. 2, 525-532 (2017).

18 Liu, S. et al. Facilitating nitrogen accessibility to boron-rich covalent organic frameworks via electrochemical excitation for efficient nitrogen fixation. Nat Commun. 10, 3898-3906 (2019).

19 Wan, Y. et al. Heterogeneous electrocatalysts design for nitrogen reduction reaction under ambient conditions. Mater. Today. 27, 69-90 (2019).

20 Guo, R. et al. Porous $\mathrm{Ni}_{3} \mathrm{~S}_{4} / \mathrm{C}$ aerogels derived from carrageenan-Ni hydrogels for highperformance sodium-ion batteries anode. Electrochim. Acta. 10, 72-79 (2019).

21 Liu, L. et al. Scalable and cost-effective synthesis of highly efficient $\mathrm{Fe}_{2} \mathrm{~N}$-based oxygen reduction catalyst derived from seaweed biomass. Small. 10, 1295-1301 (2016).

22 Lv, C. D. et al. An amorphous noble-metal-free electrocatalyst that enables nitrogen fixation under ambient conditions. Angew. Chem. Int. Ed. 57, 6073-6076 (2018).

$23 \mathrm{Li}, \mathrm{D}$. et al. Egg-box structure in cobalt alginate: A new approach to multifunctional hierarchical mesoporous $\mathrm{N}$-doped carbon nanofibers for efficient catalysis and energy storage. ACS Cent. Sci. 1, 261269 (2015).

24 Chen, $\mathrm{X}$. et al. Cationic S-doped $\mathrm{TiO}_{2} / \mathrm{SiO}_{2}$ visible-light photocatalyst synthesized by co-hydrolysis method and its application for organic degradation. J. Mol. Liq. 273, 50-57 (2019).

$25 \mathrm{Li}$, D. et al. Turning gelidium amansii residue into nitrogen-doped carbon nanofiber aerogel for enhanced multiple energy storage. Carbon. 137, 31-40 (2018).

26 Mishra, G. et al. Facile Fabrication of $\mathrm{S}-\mathrm{TiO}_{2} / \beta-\mathrm{SiC}$ Nanocomposite Photocatalyst for Hydrogen Evolution under Visible Light Irradiation. ACS. Sustainable. Chem. Eng 3, 245-253 (2015). 
27 Xing, L. B. et al. Nitrogen, sulfur-codoped graphene sponge as electroactive carbon interlayer for high-energy and power lithiumesulfur batteries. Journal of Power Sources. 303, $22-28$ (2016).

28 Su, Y. Z. et al. Sulfur-enriched conjugated polymer nanosheet derived sulfur and nitrogen co-doped porous carbon nanosheets as electrocatalysts for oxygen reduction reaction and zinc-air battery. $A d v$. Funct. Mater. 26, 5893-5902 (2016).

29 Qian, W. J. et al. Condiment-derived 3D architecture porous carbon for electrochemical supercapacitors. Small. 37, 4959-4969 (2015).

30 Farideh, J. Sulfur: not a "silent" element any more. Chem. Soc. Rev. 35, 1256-1268 (2006).

31 Vairavamurthy, A. Using X-ray absorption to probe sulfur oxidation states incomplex molecules. Spectrochimica Acta Part A. 54, 2009-2017 (1998).

32 Han, J. R. et al. Ambient $\mathrm{N}_{2}$ fixation to $\mathrm{NH}_{3}$ at ambient conditions: Using $\mathrm{Nb}_{2} \mathrm{O}_{5}$ nanofiber as a high-performance electrocatalyst. Nano Energy. 52, 264-270 (2018).

33 Xia, L. et al. Sulfur-doped graphene for efficient electrocatalytic $\mathrm{N}_{2}$-to- $\mathrm{NH}_{3}$ fixation. Chem Commun. 55, 3371-3374 (2019).

34 Xia, L. et al. S-doped carbon nanospheres: An effcient electrocatalyst toward artifcial $\mathrm{N}_{2}$ fixation to $\mathrm{NH}_{3}$. Small Methods. 1800251 (2018).

35 Ren, Y. et al. Strategies to suppress hydrogen evolution for highly selective electrocatalytic nitrogen reduction: challenges and perspectives. Energy Environ. Sci. 14, 1176-1193 (2021).

36 Zhang, W. et al. Single-crystalline $\left(\mathrm{FexNi}_{1-\mathrm{x}}\right)_{2} \mathrm{P}$ nanosheets with dominant $\{01\}$ facets: Efficient electrocatalysts for hydrogen evolution reaction at all pH values. Nano Energy. 56, 813-822 (2019).

37 Wang, K. W. et al. Boosting hydrogen evolution via optimized hydrogen adsorption at the interface of $\mathrm{CoP}_{3}$ and $\mathrm{Ni}_{2}$ P. J. Mater. Chem. A 6, 5560-5565 (2018).

$38 \mathrm{Li}, \mathrm{Q}$. et al. Electronic modulation of electrocatalytically active center of $\mathrm{Cu}_{7} \mathrm{~S}_{4}$ nanodisks by Cobalt-doping for highly efficient oxygen evolution reaction. ACS Nano. 11, 12230-12239 (2017).

\section{Figures}




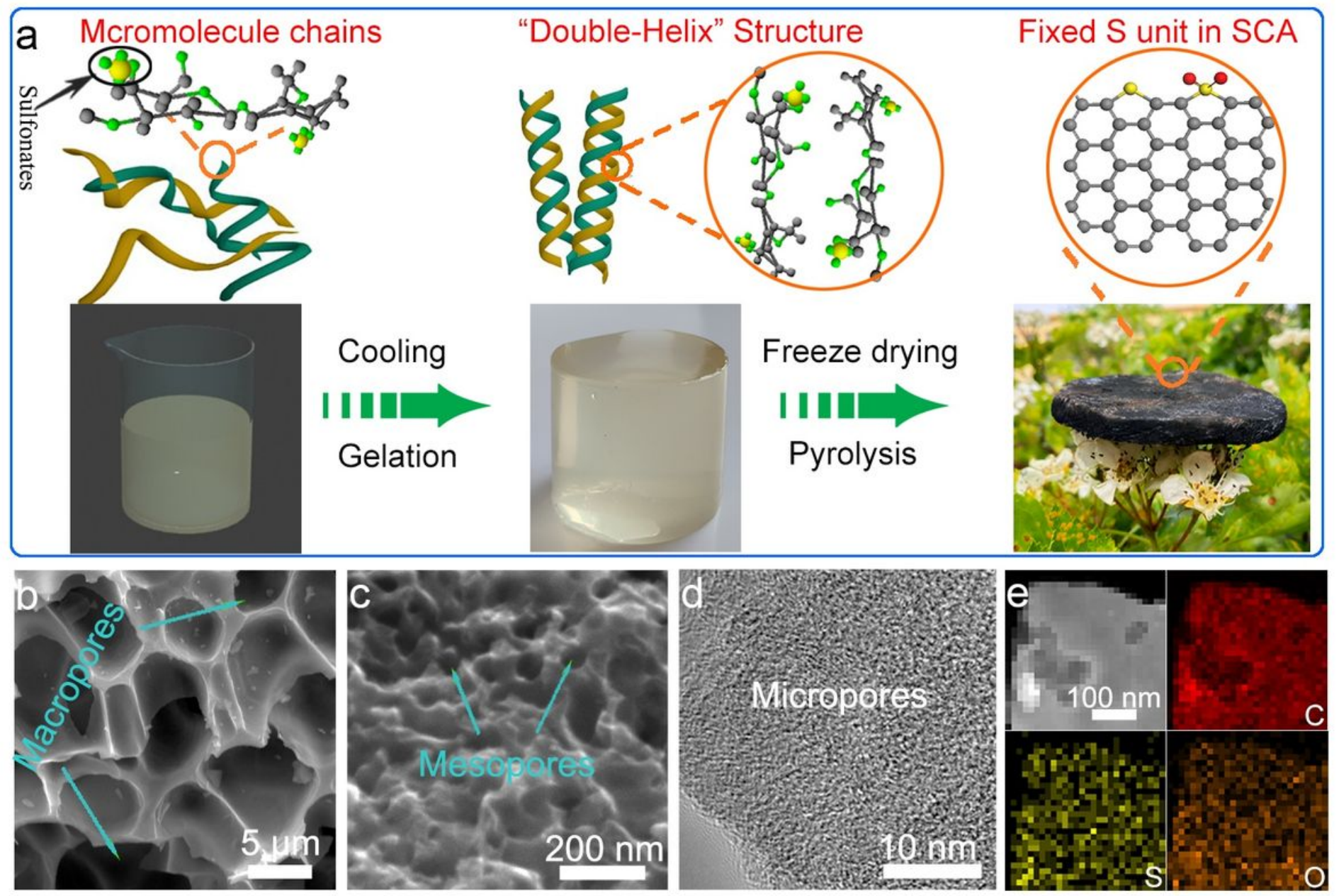

Figure 1

a, Schematic illustration on the process of marine biogenic $S$ fixation. b-c, FESEM images of SCA-700. $\mathrm{d}-\mathrm{e}$, TEM image and the corresponding EDS mappings for C, S, and 0 elements of SCA-700. 
a

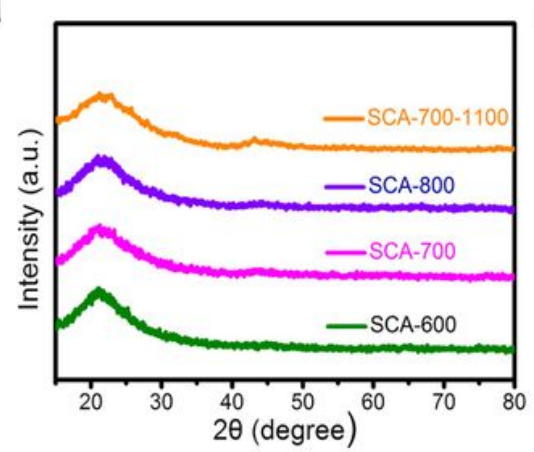

d

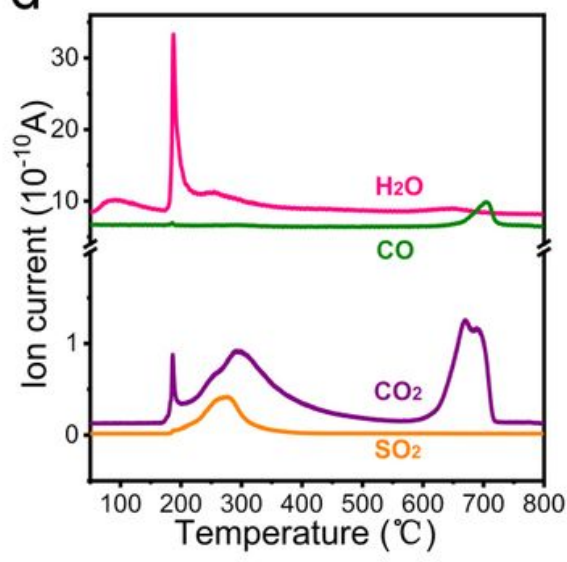

f

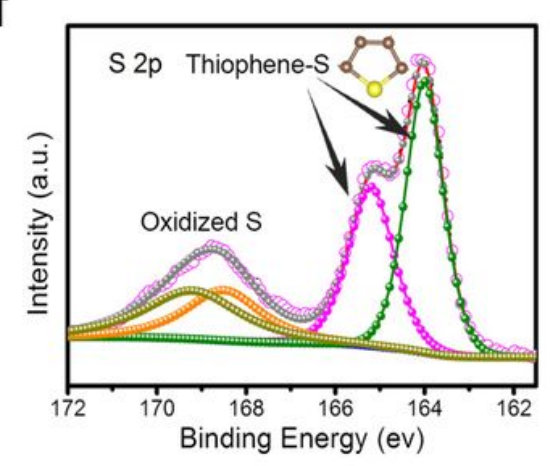

b

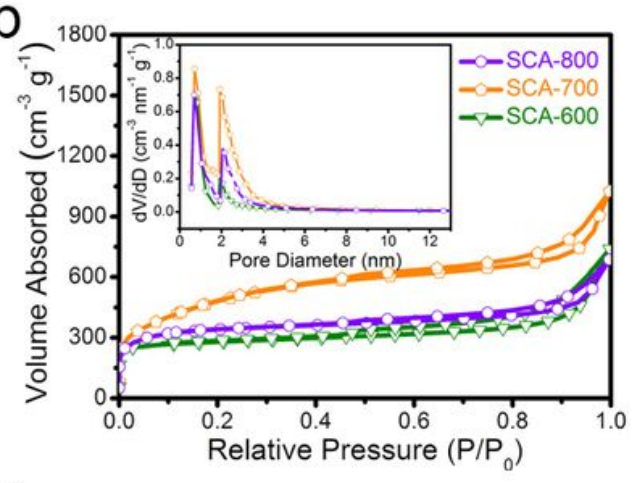

e

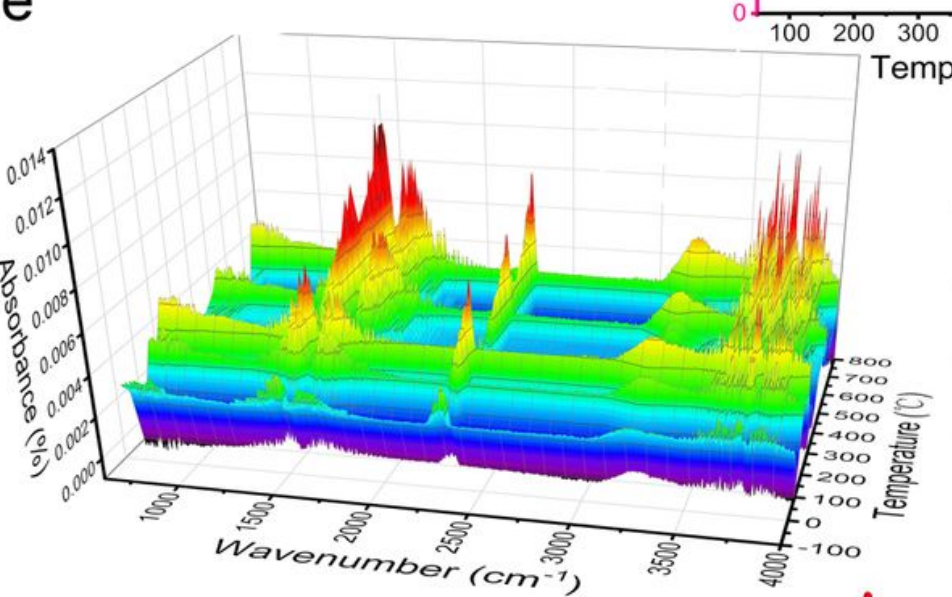

g

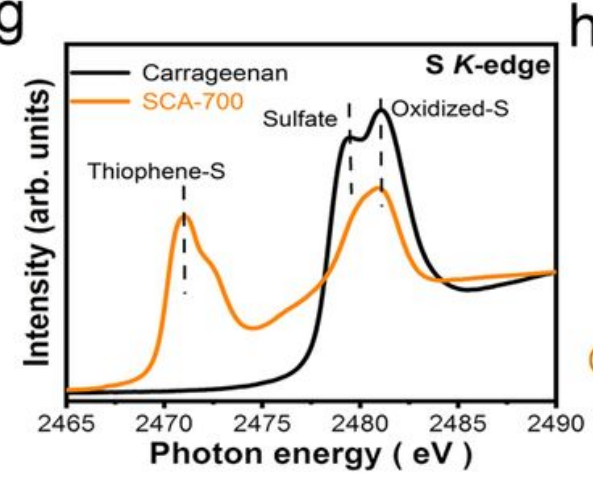

C

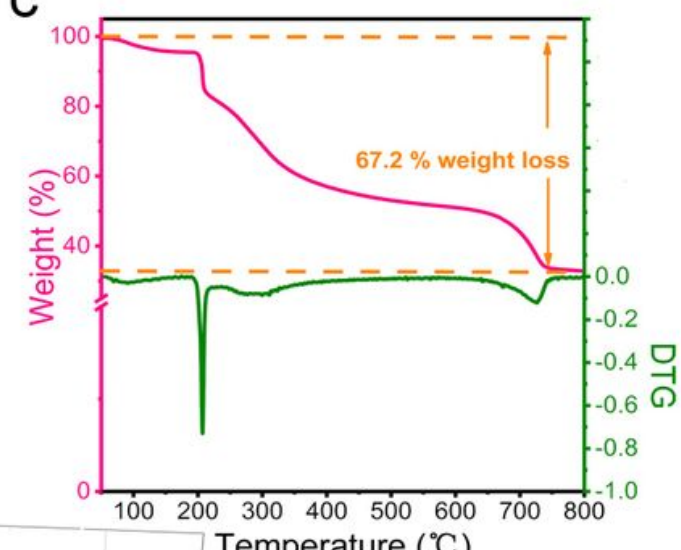

\section{Figure 2}

Characterization of SCA. a, XRD patterns of SCA-T. b, Nitrogen adsorption-desorption isotherm for SCA-T (inset: Pore size distributions of SCA-T). C, TGA and DTG curves of carrageenan aerogel in N2 atmosphere (heating rate $5{ }^{\circ} \mathrm{C} / \mathrm{min}$ ). $\mathrm{d}$, The analysis of outlet gases from the decomposition of carrageenan aerogel TG-MS: H2O (pink), CO (olive), CO2 (purple) and SO2 (orange). e, 3D TG-FTIR spectra of carrageenan aerogel. f, S 2p XPS spectra of SCA-700. g, S K-edge XAS spectra of carrageenan and SCA-700. $h$, The schematic diagram of the process of the $S$ fixation. 
a

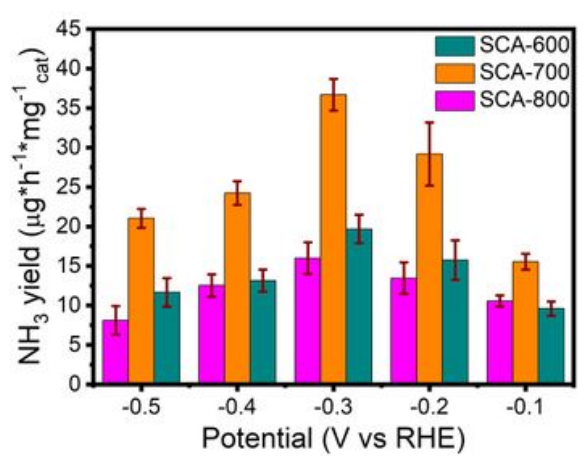

d

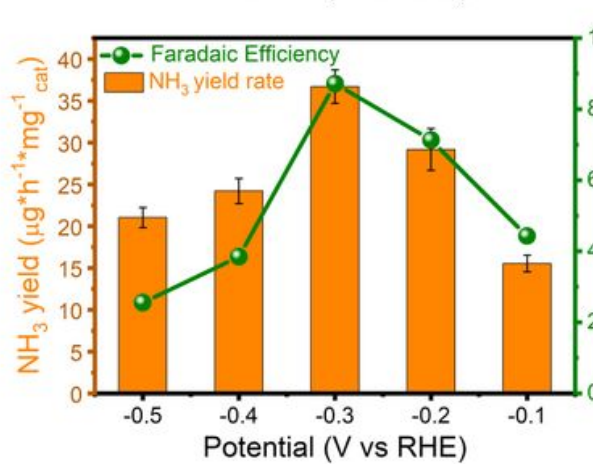

g

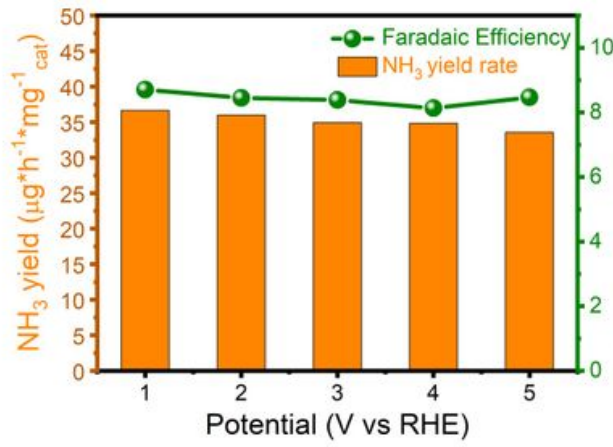

$b$

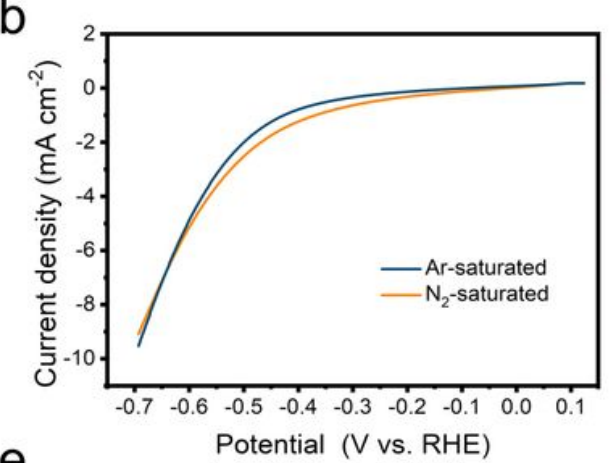

e

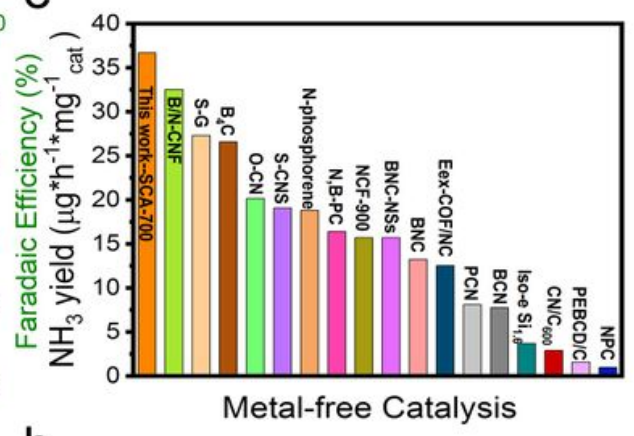

$\mathrm{h}$

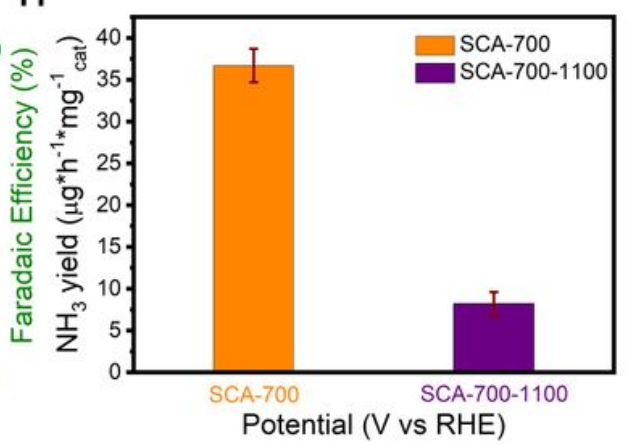

C

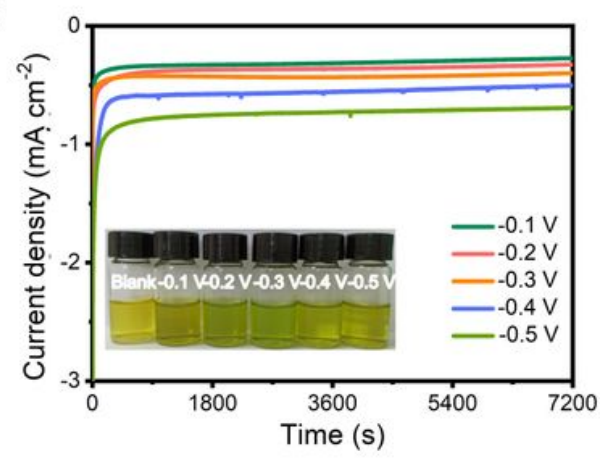

f
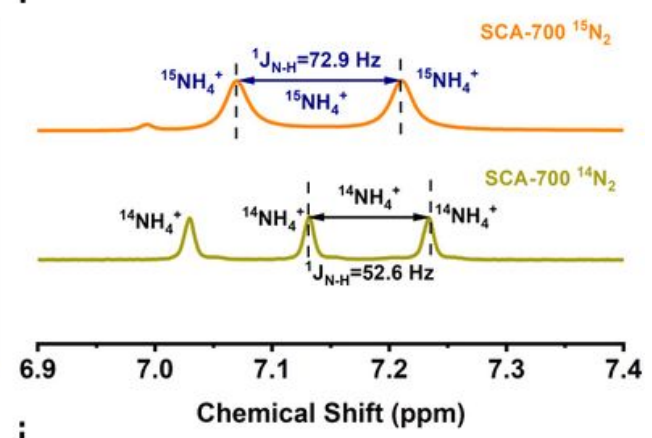

i

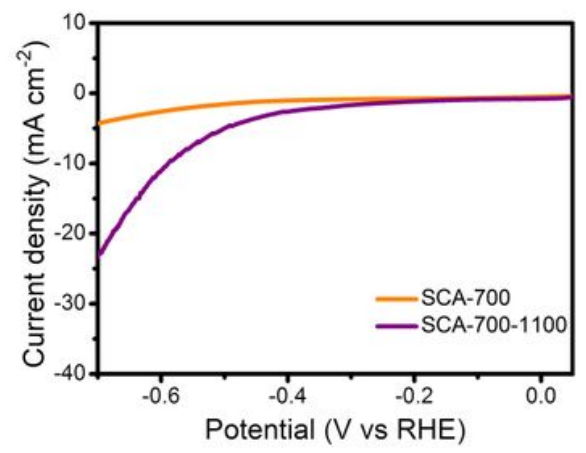

Figure 3

a, NH3 yield of SCA-T in $0.1 \mathrm{M} \mathrm{HCl}$ electrolyte. b, LSV curves of SCA-700 in Ar-saturated and in N2-saturated electrolyte. c, The corresponding chronoamperometry curves of SCA-700 at different potentials in $0.1 \mathrm{M} \mathrm{HCl}$ solution. $\mathrm{d}, \mathrm{NH} 3$ yield and FEs of SCA-700 under different potentials. e, Comparison of the $\mathrm{NH} 3$ yield rate among SCA-700 and available reported metal-free catalysts. $\mathrm{f}, 1 \mathrm{H}$ NMR analysis of the electrolyte fed by $15 \mathrm{~N} 2$ and $14 \mathrm{~N} 2$ after electrolytic reaction at $-0.3 \mathrm{~V}$. g, Cycling test of SCA -700 at $-0.3 \mathrm{~V}$. h, NH3 yield and i, HER performances of SCA-700 and SCA-700-1100. 
a
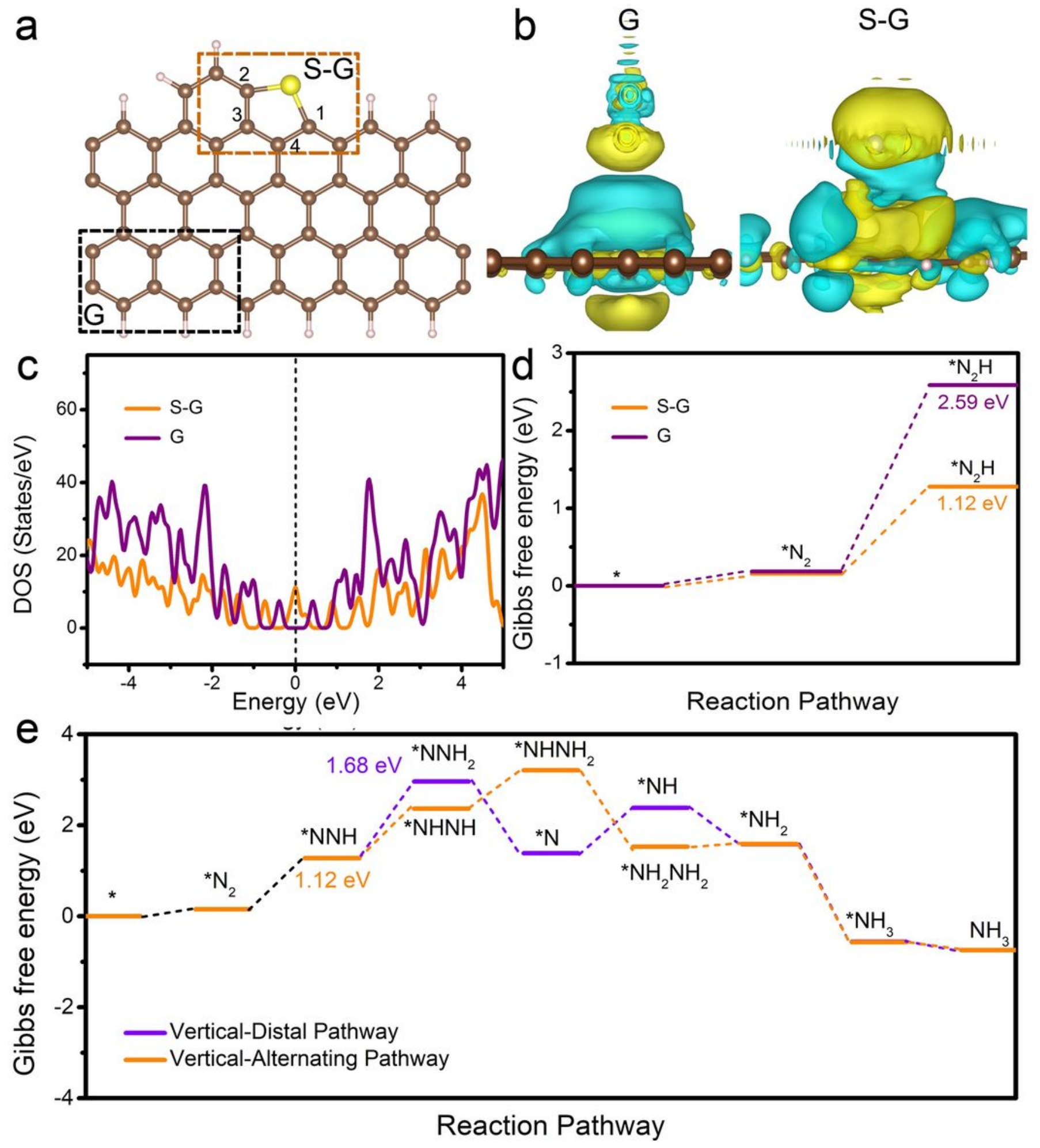

Figure 4

a, Schematic of computational models. Brown and yellow represent $C$ and $S$ atoms, respectively. $b$, The images of charge density difference at $G$ and $S-G$. The yellow and cyan color represents the charge accumulation and depletion, respectively. c, DOS of G and S-G. d, Calculated free energy diagram of *N2H for $\mathrm{G}$ and $\mathrm{S}-\mathrm{G}-2$. e, Free energy diagram of $\mathrm{N} 2$ reduction on $\mathrm{S}-\mathrm{G}$. 


\section{Supplementary Files}

This is a list of supplementary files associated with this preprint. Click to download.

- Supplementaryinformation.docx 